\title{
CANOEROS EN CHILOÉ: DE FACILITADORES DE LAS NAVEGACIONES ESPAÑOLAS EN LOS ARCHIPIÉLAGOS DE LOS CHONOS Y DE GUAYANECO, A PRODUCTORES Y COMERCIANTES, 1567-1792
}

\author{
COASTAL HUNTER GATHERERS IN CHILOE: FROM FACILITATORS OF \\ THE NAVIGATION OF SPANIARDS IN THE CHONOS AND GUAYANECO \\ ARCHIPELAGOS TO PRODUCERS AND TRADERS, 1567-1792
}

Ximena Urbina ${ }^{1}$, Omar Reyes ${ }^{2}$ y Carolina A. Belmar ${ }^{3}$

\begin{abstract}
Los canoeros de los archipiélagos bordemarinos australes trasladados a Chiloé en los siglos XVII y XVIII actuaron como conectores entre ambos mundos por tener el conocimiento geográfico sobre un medio que no podían dominar los españoles y veliches de Chiloé, siendo facilitadores forzados de las actividades de éstos en el archipiélago de los Chonos como lenguas, guías o prácticos, buceadores, vigilantes y buscadores de otros grupos indígenas. Los canoeros trasladados a las islas Cailin y Chaulinec con fines civilizatorios desde 1743 en adelante, no abandonaron del todo su territorio y volvieron permanentemente a sus islas para practicar actividades ancestrales (pescar, mariscar, consumir carne de lobo marino), pero también nuevas, como la agricultura y ganadería, aprendidas en Chiloé. Ellas fueron realizadas con el objetivo no de sobrevivencia, sino orientadas al intercambio con los habitantes de Chiloé. Los canoeros, por lo tanto, desarrollaron estrategias de subsistencia a partir de elementos presentes en su cultura, como la explotación de materiales exógenos de origen cultural (restos de naufragios) como recursos de intercambio; la adecuación al uso de técnicas y tecnologías de preparación y conservación de alimentos orientado no solo al consumo directo, la utilización de nuevos nichos ecológicos, distintos de los propiamente litorales o de las islas habituales, para acceder a otras islas que ofrecían pastos para la crianza libre de ganado europeo, entre otras prácticas que dan cuenta de una actitud activa ante el nuevo mundo que les fue impuesto.
\end{abstract}

Palabras claves: Patagonia occidental, archipiélago de Chiloé y de los Chonos, canoeros, estrategias de subsistencia, contacto español.

The coastal hunter gatherers of the southern coastal archipelagos who were transferred to Chiloe during the 17th and 18th centuries played a connecting role between these two worlds as they were familiar with the geography of an environment that could not be dominated by the Spaniards and the Veliche of Chiloé. They became forced facilitators of the activities of these groups in the Chonos archipelago, undertaking tasks as translators, guides, divers, watchers, and seekers of other indigenous groups. The canoeists transferred to the islands of Cailin and Chaulinec with civilizing purposes from 1743 onwards did not completely abandon their territory, not only returning to their islands on a permanent basis to practice ancestral activities (fishing, shellfish gathering, consumption of sea lion meat) but also bringing new occupations from Chiloé, such as agriculture and livestock breeding, which were developed for purposes of exchange with the inhabitants of Chiloé rather than for mere subsistence. As a result, these people developed subsistence strategies based on elements present in their culture, such as the exploitation of exogenous materials of cultural origin (shipwrecks remains) as exchangeable items; the adaptation of techniques and technologies for food preparation and conservation; the use of new ecological niches other than the strictly coastal inlets or the usual islands, such as islands with pastures for the free breeding of European cattle, among other practices that account for an active attitude towards the new world that was being imposed on them.

Key words: Western Patagonia, Chiloé, and Chonos archipelagos, Coastal hunter gatherers, subsistence strategies, Spaniard contact.

\footnotetext{
${ }^{1}$ Instituto de Historia, Pontificia Universidad Católica de Valparaíso, Valparaíso, Chile. maria.urbina@ @ucv.cl

2 Centro de Estudios del Hombre Austral, Instituto de la Patagonia, Universidad de Magallanes, Magallanes, Chile. omarreyesbaez@gmail.com

${ }^{3}$ Departamento de Antropología, Facultad de Ciencias Sociales, Universidad de Chile, Santiago, Chile. carolina_belmar@hotmail.com
} 


\section{Los Archipiélagos Bordemarinos Australes bajo la Influencia de Chiloé Colonial}

El sistema archipielágico distribuido en el borde occidental austral del continente americano desde el canal de Chacao y hasta la península de Taitao $\left(41-47^{\circ} \mathrm{S}\right)$, estuvo poblado por distintos grupos canoeros cazadoresrecolectores marinos llamados genéricamente chonos (Álvarez 2002; Cooper 1946). La fundación de Castro, en 1567, fue el comienzo de la ocupación española permanente de Chiloé. Aunque se impuso la nueva cultura, ello no hizo desaparecer el sustrato originario de veliches (huilliches) y payos, además de los canoeros trasladados a ese archipiélago, lo que dio origen a una sociedad multicultural.

En el período Colonial Chiloé se proyectó culturalmente de forma progresiva hacia los archipiélagos del sur, con objetivos económico-extractivos, misionalesextractivos, y exploratorios (Urbina 2013). En esta proyección entre el mundo español-veliche de Chiloé y el canoero podrían distinguirse tres modalidades. $\mathrm{La}$ primera son las malocas, práctica habitual utilizada por los españoles para capturar individuos y venderlos como esclavos. Se navegaba hacia las islas del sur de Chiloé para obtener estas piezas desde fines del siglo XVI. Conocido esto por los jesuitas que llegaron en 1609 a Chiloé para fundar una misión, provocó su interés por concentrar a los chonos en una de las islas Guaitecas (1609-1630 aproximadamente) para intentar que dejasen la vida errante, lo que no se consiguió. A partir de entonces las Guaitecas fueron la puerta de entrada al mundo canoero, primera escala en cualquier navegación hacia el sur.

El bordemar fue en un comienzo, un espacio de malocas. El intento misional jesuita no puso fin a ellas, sino que constan en registros hasta comienzos del siglo XVIII (Urbina 2017). Con el abandono de la misión de las Guaitecas tampoco se agotó la extracción de personas con fines misionales, segunda modalidad en nuestro esquema, que se mantuvo hasta fines del siglo XVIII. La estrategia de control y traslado de canoeros (Casanueva 1982) tuvo una segunda etapa entre 1743 y 1780, cuando el naufragio de la fragata inglesa Wager en el archipiélago de Guayaneco en 1741 abrió otra puerta hacia los archipiélagos, y grupos de individuos fueron atraídos por los religiosos para trasladarlos a islas del mar interior de Chiloé. El naufragio propició una nueva ruta al sur, porque dio a conocer a los españoles y veliches el camino de canoeros a través del istmo de Ofqui.

Una tercera modalidad es la proyección de los españoles y veliches de Chiloé hacia el espacio insular patagónico, como un área de explotación de bienes y de materias primas diferentes a las piezas o neófitos trasladados. Esta fue con fines extractivos y a manera de enclaves, es decir, sin ocupar esas islas y costas, por no ser valoradas ni por sus riquezas minerales ni por ser tierras agrícolas o ganaderas. Chiloé, por lo tanto, entre los siglos XVI y XVIII se aproximó al litoral austral o para extraer mercancías (indígenas para la venta o para su "civilización", explotación de naufragios); para buscar la oculta ciudad de los Césares; o cuando, por orden del gobernador insular o de las autoridades peninsulares, se navegó hacia la boca del estrecho de Magallanes para vigilar que no hubiese competidores europeos intentando poner una base en las tierras que España entendía como propias.

\section{Propuesta}

El mundo canoero ha sido descrito como sujeto pasivo frente al contacto con los españoles-veliches entre los siglos XVI y XVIII (Byron 1768; García 1767), y la bibliografía ha seguido esta interpretación (Barros 1975; Urbina 2007). Creemos, en cambio, que las tres modalidades o claves interpretativas que proponemos como definitorias del modo de vinculación de Chiloé con el espacio patagónico insular, permiten afirmar que no se operó sobre una población pasiva, sino que los canoeros desarrollaron estrategias adaptativas que los muestran como una población que se involucró activamente en su nueva realidad ante el mundo español. Centraremos este artículo en ese papel y actitud. La lectura de las fuentes escritas disponibles muestran cómo los canoeros trasladados a Chiloé no quedaron confinados a esa relocalización, sino que volvieron constantemente a los lugares desde donde fueron extraídos, llevando consigo elementos culturales foráneos ya adquiridos.

Sabemos por las investigaciones arqueológicas y registros bioantropológicos realizados en el archipiélago de los Chonos que la ocupación humana de este sistema insular se realizó por grupos cazadores-recolectores pescadores marinos desde el Holoceno Medio hasta el contacto europeo (6260-330 años cal AP) (Reyes 2017; Reyes et al. 2015; 2016). La fragmentación y distancias de este extenso espacio influyó en el desarrollo de un sistema de alta movilidad y amplios rangos de acción solo posibles a través de la utilización de canoas por parte de grupos con tecnología especializada fundamentada en la explotación del medio litoral y marino, tal como lo señalan sus conjuntos tecnológicos, arqueofaunísticos y la información dietaria de restos humanos (Belmar et al. 2018; Reyes et al. 2019).

Creemos que después del contacto, los chonos no iniciaron solamente un camino que los llevó hacia un desmantelamiento cultural (Reyes et al. 2019), sino que además se adaptaron a las nuevas condiciones de contacto interétnico, dinámicas marcadas por la asimetría, el trabajo forzado, la relocalización obligada y la asimilación con un modo de vida diferente. "Actuaron" bajo el sistema español de tres maneras. Primero, dando lugar a nuevos lugares habitados en el archipiélago chilote, como resultado de su extracción y traslado. Segundo, como 
facilitadores forzados de las actividades realizadas por los españoles en el archipiélago de los Chonos. Y tercero, como explotadores de recursos, saliendo temporalmente desde las islas donde estaban asentados en Chiloé hacia el sur, para producir y extraer elementos destinados al comercio. Estas y otras actividades se advierten en el siglo XIX, dando cuenta de un archipiélago que, para entonces, no era un espacio vacío (Núñez et al. 2016) (Figura 1).

\section{Extracción y Traslado de Canoeros: Malocas y Misiones (Islas Guaitecas, Guar, Chaulinec y Cailin)}

Las malocas, primera actividad extractiva en el archipiélago de los Chonos, es una realidad someramente conocida por la falta de fuentes (Casanueva 1982:20; Contreras et al. 1971:15; Urbina 2017). El concepto que los coronados (de Chiloé) tenían de los huilli en 1558, era la relación del chono con su territorio así como entre los distintos grupos canoeros, por ejemplo, haciendo que se escondiesen del peligro, o participando del interés foráneo ofreciendo a otros hombres en intercambio. En 1609 el cacique chono Pedro Delco iba a sus negocios a Chiloé (Quiroz y Olivares 1988). Más específico es lo que consta en 1621: el cacique Diego, hijo de Pedro, vendía públicamente chonos en Chiloé, y que los navíos que salían de Chiloé van cargados de chonos, que los venden como esclavos (Contreras et al. 1971:39, nota 49).

Los jesuitas utilizaron a Pedro Delco como herramienta para lograr atraer a chonos y trasladarlos a una de las islas Guaitecas. Con su ayuda se les reuniría y "civilizaría", separados de los españoles. Las sencillas capillas levantadas eran atendidas ocasionalmente, no teniendo misionero residente, y no se lograba reducirlos a la vida sedentaria, ni estacional ni permanente. La documentación da cuenta de una

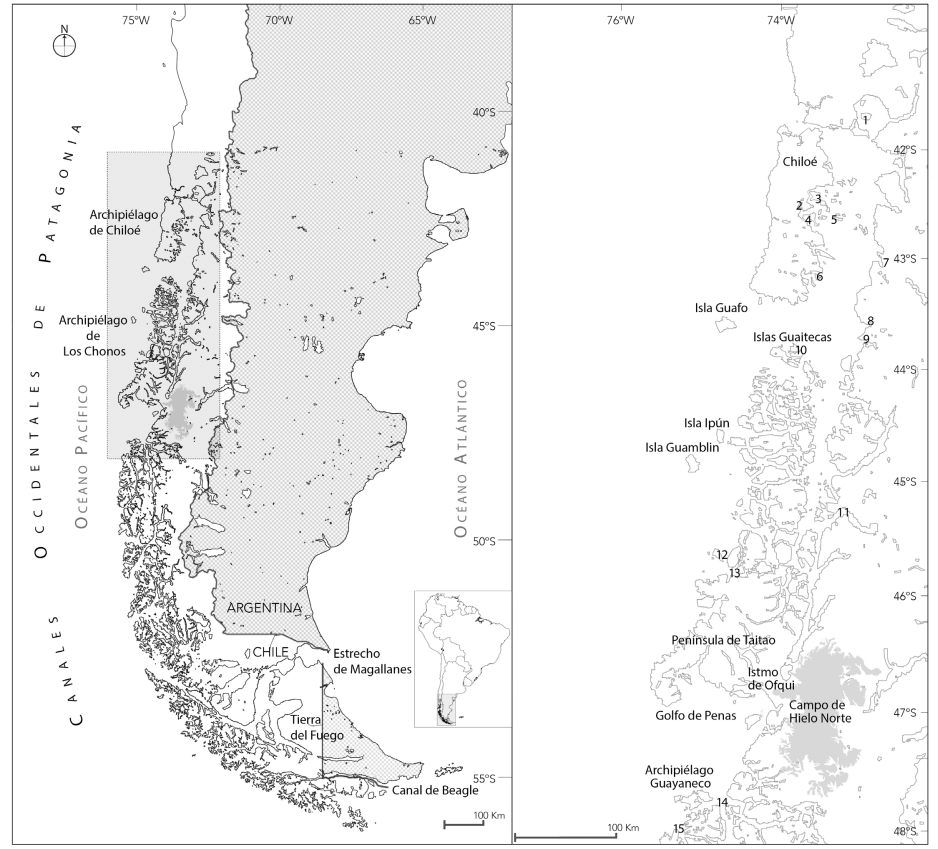

Figura 1, Mapa geográfico de Patagonia occidental y principales lugares mencionados en el texto. 1. Isla Guar, 2. Castro, 3. Isla Quinchao, punta Chequian, 4. Isla Lemuy, 5. Isla Chaulinec, 6. Isla Cailin, 7. Estero Palvitad, 8. Bahía Tictoc, 9. Estero Palena y entrada a canal Refugio, 10. Islas Guaitecas, canal Puquitín, 11. Estero Aisén, 12. Bahía Ana Pink, 13. Isla Tenquehuén, 14. Canal Messier, 15. Canal Fallos.

Geographical map of western Patagonia and main locations mentioned in the article. 1. Isla Guar, 2. Castro, 3. Isla Quinchao, punta Chequian, 4. Isla Lemuy, 5. Isla Chaulinec, 6. Isla Cailin, 7. Estero Palvitad, 8. Bahía Tictoc, 9. Estero Palena and entry to canal Refugio, 10. Islas Guaitecas, canal Puquitín, 11. Estero Aisén, 12. Bahía Ana Pink, 13. Isla Tenquehuén, 14. Canal Messier 15. Canal Fallos.

de ser valientes y buenos guerreros (Goicueta 1558:42), lo que podría haber provocado el interés de los españoles de Chiloé para pacificar su frontera sur, amparados por el argumento de defender a los indígenas de Chiloé de antiguos o contemporáneos ataques de los huilli o chonos.

La valoración que los españoles daban a los individuos como piezas de comercio alteró gravemente progresiva despoblación hacia el sur: en 1631 se fue a buscar preciosas margaritas a 30 leguas distantes de Castro (Letras anuas 1631), y se entiende que es al sur del golfo de Penas: había que ir más lejos para hallarlos. Además, ya no se les describe como a Delco, sino como personas más rústicas, desnudas, y que usaban canoas de cortezas, no de tablas (Letras anuas 1659; Rosales 
1877, I:105). Esto es señal que se había accedido a grupos distintos a los chonos más australes, que fueron llamados cau cau, aunque en el siglo XVIII hubo otros nombres que corresponderían a grupos o identidades diferentes. Todos ellos bien pueden ser considerados antiguos kaweskar. En 1639, la carta anua (Memorial 1642) habla de la provincia de los chonos como un lugar ya no visitado por jesuitas. Suponemos que los atraídos fueron solo algunos y que el arraigo fue escaso.

La alteración del archipiélago de los Chonos, con extracción y traslado por malocas o por misiones a la isla Guaiteca grande, hizo que en 1710 llegaran 166 chonos a Chiloé manifestando -dice la documentación española- su deseo de vivir allí (Urbina 2017:396). Los jesuitas obtuvieron su tutela y les llevaron a la isla Guar, separados de los españoles y otros indígenas. En 1722 se denunció que los jesuitas los hacían trabajar en una estancia (Casanueva 1982:21). El abuso es quizá uno de los motivos por el que los chonos fueron dejando Guar y desperdigándose por las costas, lo que motivó que en la década de 1730 los jesuitas trasladasen la misión desde Guar a la isla Quinchao, situándola en la punta de Chequian. Pero cuando el obispo Azúa visitó Chiloé en 1741, comprobó que la cantidad de neófitos de la misión de Chequian era muy escasa (Moreno 2008:195). Hasta entonces, por lo tanto, la misión de Guaitecas era inexistente; los chonos trasladados como piezas y que habían permanecido en Chiloé no constituían un grupo, sino que eran individuos aislados, y los $166 \mathrm{de}$ Guar de 1710 se movían por el mar interior de Chiloé y el archipiélago de los Chonos, sin que los documentos reflejen nada relativo a ellos.

En 1741 ocurrió el naufragio de la fragata inglesa Wager (Byron 1768). Dicho episodio fue catalizador de movimientos. Olleta, señalado en la documentación como cacique chono, llegó al sitio del naufragio un año después, habiéndose trasmitido de sur a norte la noticia, y condujo a los pocos sobrevivientes a Chiloé. Es interesante destacar que Olleta, cacique de Cailin, daba valor al metal que llevaba el barco. Las autoridades españolas se enteraron de los 28 cañones que la fragata llevaba. La llegada de expediciones provenientes de Chiloé a buscar los cañones y el metal en general (Urbina 2015) puso de manifiesto la existencia de un grupo de lengua distinta a la de los chonos, eran "de tan remotas islas que median dos distintos idiomas al suyo" (Expediente 1744:19). Se les llamó caucahues, y fueron trasladados progresivamente a islas del mar interior de Chiloé para su "civilización”, lo que quedó en manos de los jesuitas.

Treinta personas en seis dalcas con Ignacio Assilacui como cacique fueron dejados en la isla Chaulinec a comienzos de 1743 (Expediente 1744:19), donde había ya asentados parte de los antiguos chonos de Guar. A comienzos de 1744 otros caucahues fueron llevados por Abraham Ervrard (Historia geographica c. 1760:133v), mismo año en que hubo numeración en las islas Chaulinec y Cailin. En esta última había 50 chonos, según dijo su gobernador Olleta, incluyendo también a "los que viven en las islas más remotas [...] donde solo ellos transitan, como es Guapiquilán, Quilán y otras” (Expediente 1744:41). En la de Chaulinec, según su procurador, Diego Chaneu, había 81 guaiguenes (Expediente 1744:41v). Aunque hablaban la misma lengua, se reconoce una diferencia entre los chonos llegados en 1720 y los trasladados desde 1743: a los antiguos se les llama chonos y a los segundos, guaiguenes, chonos o chonos guaiguenes.

En la misma matrícula requerida por el gobernador de Chiloé consta que los que hablaban una lengua desconocida, los caucahues, del "Desecho que va al paraje de Guayaneco", según lo informado por Don Ignacio Astillaco, su gobernador, eran 90. Y dice, "aunque hay muchos indios habitantes por aquellos parajes, no los conoce por estar ultramarinos de donde reside" (Expediente 1744: 41v). Lo anterior muestra cómo el golfo de Penas fue un área en que confluían diferentes grupos, etnias o identidades (Álvarez 2002). Estos supuestamente nuevos hallados no lo eran realmente, porque las expediciones misionales y militares del siglo anterior habían contactado con ellos: los caucau y otros grupos, antiguos kaweskar, como ya se ha dicho.

Guaiguenes y caucahues fueron dejados en Chaulinec. A los chonos "antiguos", de los que Olleta era cacique se les atribuía residencia en Cailin. Los traslados con separación residencial y fines civilizatorios cubrieron las décadas siguientes. Hubo 40 trasladados en 1745 (Urbina 2012:213). Pronto Chaulinec se menciona mucho menos que Cailin en la documentación, y es a esta isla donde se empezó a atribuir la existencia de caucahues. En 1754 había 200 "caucahues" en ella (Instrucción 1754). Se consiguió la fundación formal de misión en la isla en 1764, como puerta de entrada a las nuevas naciones hacia el Estrecho, y los jesuitas García (1767) y Vicuña (1768) fueron a buscarlas. Para 1773 los canoeros ya estaban en Chiloé o se habían movido de sus territorios habituales, porque ese año el gobernador insular dijo que los archipiélagos de Guaitecas y Chonos estaban deshabitados (Beranger 1773, f. 6). Los viajes de franciscanos Marín y Real, en 1778-1779; Fernández y Sánchez, en 1779; y Menéndez y Vargas, en 1779. 1780 , vieron a pocos canoeros, y solo en los canales al sur del golfo de Penas (Urbina 2017).

Los chonos no permanecieron en la residencia atribuida, sino que se movieron en el mar interior de Chiloé y hacia el sur, de forma temporal o permanente, dado que, como neófitos y en un contexto del siglo XVIII, no se les retenía por la fuerza al no ser valorados como buenos trabajadores, ni eran tributarios. Sabemos, por ejemplo, que Domingo Huenupal, chono guaiguen, 
apreciado práctico del archipiélago de los Chonos, para el verano de 1750 estaba en canal Puquitin, de las Guaitecas (Brizuela 1750:2). Las fuentes no permiten saber más, sino solo que los 35 llevados a isla Lemuy en 1779 "antes de un año se fueron todos en una piragua" (Moraleda 1796:46), abandonos que se hacen portando elementos culturales exógenos. Los que se quedaron en la misión de Cailin se fueron trasladando con el tiempo a la isla Chaulinec, al punto que en la década de 1780 se aprueba el abandono de la misión "por estar solitaria y retirada al sud, y se han trasladado a la de Chaulinec [los franciscanos], en la que están viviendo con los neófitos chaulineques” (González 1788: 167v). En 1792 en Chaulinec ya no había misión, sino que los neófitos acudían a la parroquia de Queilen (Moraleda 1796:82v).

Las fuentes mencionan la incapacidad de los dejados en Guar y los trasladados a Guaitecas, Cailin y Chualinec para vivir como se esperaba, es decir, siendo agricultores con residencia fija. Sin embargo, en los chonos llegados en 1720 y que no se fueron del todo, y los que llegaron desde 1743 en adelante, se registran cambios en sus formas de asentamiento y de movilidad, por haber una habituación a las maneras españolas y un intento por participar en el nuevo escenario ofrecido.

\section{Los Canoeros como Facilitadores Forzados de Navegaciones por los Archipiélagos del Sur de Chiloé}

La presencia española generó relaciones asimétricas al interior del mundo canoero. Los elementos materiales introducidos en las malocas y correrías misionales pudieron haber desequilibrado las relaciones de poder al interior de los grupos y entre grupos distintos. También, por la valoración de determinados individuos por sobre otros, por ejemplo, con la atribución de la categoría española de caciques.

Pero no solo se trata de caciques. El conocimiento de su territorio fue valorado como una herramienta logística que permitía el acceso y circulación por ese espacio, tanto para llegar a determinados lugares como para conseguir recursos alimentarios durante el trayecto. El interés español por algunos de ellos debió generar cambios en la estructura social de una comunidad que ha sido descrita como igualitaria, sin grandes diferencias de jerarquías ni disputas por el poder (Cooper 1946).

Una de las funciones atribuidas a canoeros para el servicio de los españoles es el ser lenguas (informantes). La documentación permite conocer algunos casos en que canoeros dieron información sobre otras tierras, actuando como conectores entre el mundo español y los archipiélagos australes (Urbina 2016). Estas noticias fueron de la existencia de grupos indígenas aun no contactados, de españoles aislados en tierras lejanas, o supuestas colonias de holandeses o ingleses, todas informaciones que siempre originaron nuevas expediciones de reconocimiento (Urbina 2013).

Diego de Rosales menciona al indio Atapa, tomado en una "entrada" de 1640, que una vez en Chiloé fue el informante que dio pie a una expedición al año siguiente (Rosales 1877, I:105). A su vez, Cristóbal Talcapillán, considerado chono, fue tomado en una "entrada" en 1674 y conducido al fuerte de Chacao. Parece que era una práctica el trasladar individuos para que, habituados a los españoles y ya más capaces de darse a entender, informasen de las posibles novedades de sus tierras. Talcapillán dijo que había dos colonias inglesas en las costas del sur y su noticia generó dos formales expediciones de búsqueda en los años siguientes, y la sospecha de haberlas perduró en la metrópoli y en la cartografía durante décadas. Más tarde, el cacique Olleta fue alertado por otros grupos, distintos al suyo, del naufragio de la Wager. Él conectó a los sobrevivientes con Chiloé. Asimismo, en 1762 dice el gobernador de Chiloé sobre el río Palena: "quiero desegañarme de este formidable río, que por noticias que me han dado los indios guaiguenes interna mucho a la parte del este dejando las cordilleras atrás y me aseguran haber población sin saber qué nación sea" (Garretón 1762), para lo cual enviará un barco.

Son informaciones de lo que hay en un enorme territorio sin presencia española alguna, valoradas como noticias, dadas por informantes que son como puertas a nuevas realidades: abren nuevos mundos, crean nuevos espacios.

Otra función asignada a los canoeros es el de ser prácticos. Normalmente los lenguas, siempre hombres, actuaron de prácticos, es decir, guías de la navegación en las expediciones que se implementaron producto de las propias noticias que dieron. Indicaban dónde hallar lo buscado, los caminos a seguir, las maneras de transitarlo, los lugares donde resguardar la piragüa, donde alimentarse, etc.

El capitán García Tao llevó consigo al Delco de los jesuitas en 1620, para buscar a los Césares; Rodrigo Navarro llevó a Atapa a lo mismo en 1641, y en 1674 Bartolomé Gallardo, y al año siguiente, Antonio de Vea, llevaron a Talcapillán a buscar dos colonias inglesas. Cuando se envió a Brizuela en 1750 a la actual bahía Ana Pink a levantar un fuerte (para evitar que sea ocupada por Inglaterra), llevó al guaiguen Domingo Huenupal, por ser principal práctico de Tenquehuen. Él sabía dónde había recalado en 1741 el barco $L a$ Anna, de la flota de Anson. Domingo fue también en la expedición de 1768, comandada por Mansilla y Ugarte a la isla Madre de Dios, por sospecharse haber allí un enclave inglés: en la lista de expedicionarios se le antepone un Don a su nombre (Testimonio 1768:35). A esa misma isla volvió de práctico con Joseph Rius en 1770 (Diario 1770). 
La expedición de Nicolás Lobato y Cuenca, en 1792, llevó como uno de sus prácticos a un hijo de Domingo, Antonio Guenupal, "excelente práctico de toda la ensenada y puerto, pues de dos en dos años corre todos estos parajes". Otro fue Domingo Llapa, gobernador de Chaulinec. Antonio Huenupal y su hermano Luis fueron con el piloto Moraleda al reconocimiento del archipiélago de los Chonos, en 1792 y 1793. Moraleda los califica como guihuenes y dice que son de los trasladados a Cailin y luego a Chaulinec. Además de los ya dichos, lleva a otros dos: Pedro Yaña y Manuel Tuba (Diario 1792).

Otro práctico señalado en las fuentes -sin nombre, quizá el mismo Domingo Huenupal- fue el que llevó José Domínguez en 1763 en su expedición a Tenquehuen. Moraleda informa que Silvestre Mariantigue, uno de los guaiguenes de Cailin, fue a la expedición que llegó más al sur del golfo de Penas con el jesuita Vicuña en 1768 (Moraleda 1796:83). Silvestre fue después con Lobato, quien dice que es natural de Guayaneco, y ha pasado siete veces con los misioneros el istmo de Ofqui (Diario 1792:15). Después fue práctico de Moraleda.

Los prácticos apenas son individualizados en las fuentes, pero no por eso inexistentes. Al contrario, fueron vitales para determinar singladuras y tomar decisiones. Los españoles llevaban a varios, para cubrir diferentes lugares: el guaiguen Domingo Huenupal era práctico para las islas más meridionales y occidentales del archipiélago de los Chonos, y Silvestre Mariantihue, guihuen natural de Guayaneco, lo era para Ofqui, golfo de Penas y más al sur.

Moraleda es la mejor fuente para acercarse a ellos. Dice que el nombre de prácticos "lo merecen con justicia para estos canales [...] sin embargo la rudeza que les es común". Le cree a Yaña, por ejemplo, porque ha observado exactitud en sus noticias, y dice que pondrá en su carta la existencia de las islas Huamblin e Ipun, porque aunque no fue hacia ellas, los prácticos informaron su existencia.

Ellos muestran el mundo, nominan lo nuevo, dicen que hay más allá de lo que se ve, advierten y señalan dónde y cuándo hay que comer. Eran aprovechados por su conocimiento y experiencia en viajes sucesivos. Como único dato sobre retribución sabemos que en la expedición de 1763 se pagó al práctico con un poncho, cuyo valor era un peso y 7 reales. Era un oficio o quizá dignidad, que podía traspasarse de padre a hijos, como es el caso de los Huenupal.

Una tercera función atribuida a canoeros para el servicio de los españoles es la de indias buzas. Su rol como mariscadoras en el mundo canoero ha sido descrito. Los españoles aprovecharon esta especialización en otras tareas distintas, como sacar a flote cosas sumergidas. Cuando el barco comandado por el piloto Vea naufragó en 1675 el canal de Chacao, descartándose ya la posibilidad de recuperar lo más, "envióse a traer una india buza de nación chona nueve leguas de aquí para que buscase lo más preciso para mi viaje" (Vea 1675:585v); y cuando en 1789 naufragó en Guapilacuy la fragata Balvanera, se llevaron buzos (no dice buzas) guaiguenes, a quienes se dio bastimento durante el período de la faena (Cajas Reales 1789). Abraham Evrard, en 1743, llevó buzas junto a sus maridos para sacar los cañones de la Wager del fondo marino. Los guaiguenes, asimismo, también llevaron a sus mujeres a dicho naufragio para sacar hierro por su cuenta y venderlo en Chiloé, como también iban cuatro buzas en la piragua defraudadora habilitada por los jesuitas para buscar metal.

Como vigilantes, también facilitaron la presencia de los españoles en las costas del sur. Sin que se trate de un sistema organizado de patrullaje, los chonos eran considerados vigilantes de las costas del sur en servicio del rey, cooperadores en la defensa. Informó el gobernador de Chiloé al presidente de Chile: "acabo de tener aviso cómo un navío se haya varado y que uno de los mencionados indios que vigilan a dichas islas halló hombres extranjeros" (Gutiérrez de Espejo 1742), refiriéndose a Olleta. Las sospechas que desde la metrópoli se tenían de haberse concretado la instalación una base inglesa en las costas australes generaron órdenes de vigilancia que ejecutaba el gobernador insular mediante expediciones a cargo de pilotos y oficiales, que llevaban siempre prácticos chonos y remeros veliches. Pero también se enviaban a caciques para aquella tarea, quienes habilitados por la autoridad con chiguas de papas y carne de vacuno, iban en sus dalcas. Fue el caso de la vigilancia hacia las islas Tenquehuen y Madre de Dios $\left(50^{\circ} \mathrm{S}\right)$ que cubrió las décadas de 1750 a 1770 . Un ejemplo: dice el gobernador de Chiloé en 1771 sobre la isla Tenquehuén: “... para este fin tengo comandado a los indios guaiguenes, que navegan continuamente el archipiélago, con cargo a sus caciques, que cualquier embarcación que avisten o novedad que ocurra, me den luego cuenta" (Información 1771).

Por último, otra función asignada por los españoles fueel ser buscadores de indígenas. Los jesuitas emplearon a los chonos y otros grupos conocidos con posterioridad al citado naufragio, como facilitadores para la búsqueda y atracción de otros canoeros. Se valieron de ellos, ya algo españolizados (cristianos, dirían los jesuitas) para que en sus dalcas y habilitados por los jesuitas, buscasen a grupos nuevos. Debían explicarles que en Chiloé, a cargo de los misioneros estarían mejor que esparcidos en islas buscando el alimento diariamente. Estos conectores los atraían con objetos interesantes y les encargaban que al verano siguiente, cuando volviese con el padre, hubiesen reunido a más de sus familiares.

Probablemente Pedro Delco haya sido el primero. Sabemos que en la década de 1630 se envió a un chono a predicar a los payos, que vivían al sur de los chonos: hecha la tarea, le siguió el padre Juan López 
Ruiz (Vida del padre 1991:230). Asimismo, los tres párvulos que el jesuita Esquivel condujo a Chiloé desde el naufragio, fueron instruidos y posteriormente enviados junto a otros guaiguenes a su tierra, "a fin de que informasen el buen tratamiento que se les había dado y de atraer a otros". Volvieron 40 personas, que se destinaron a Cailin. La empresa, como se ha dicho, se repitió en los años sucesivos, llegando el número a 200 en 1754 (Instrucción y Noticia 1754). Una vez fundada formalmente la misión de Cailin, se enviaron caucahues con dos piraguas y bastimentos para reconocer lo que prometían estas tierras del sur. Volvieron a los seis meses con indígenas de la nación calen, lo que dio origen al viaje de José García, quien fue con 34 de aquellos caucahues.

Conocemos algo más los movimientos de la segunda mitad del XVIII hacia el sur del golfo de Penas con fines misionales, que los de la época anterior en el archipiélago de los Chonos. El jesuita García dice en su Diario que los regalos generaron problemas entre ellos:

El año antecedente, por noticias que les dieron los caucahues que enviamos de nuestra misión, supieron que este iba el padre misionero a sus tierras a buscarlos, y así juntaron porción de indios calenes, taijatafes, cerca de Guayaneco, deseosos los más de ser cristianos. Pero el demonio, que no descuida, metió cizaña entre ellos. Los primeros disgustos fueron porque los calenes no daban a los taijatafes parte de las chaquiras que el año antes habían recibido de la misión de Cailín por medio de los caucahues. A esto se juntó el acordarse de guerras y muertes antiguas, por lo cual tuvieron su guerrilla, aunque sin muertes, y luego se deshizo la junta, y unos quince o veinte días antes que yo llegase se fueron a sus tierras, quedando solos estos que hallé, que refirieron lo dicho (García 1767:572).

Las chaquiras y donecillos alteraron el modo de vida. En las tres expediciones de los años a cargo de los franciscanos, éstos reportaron ser los propios indígenas quienes los buscaban, conscientes ya de su posible llegada, y unían sus piraguas al grupo para irse con ellos a Chiloé.

Los lenguas, los prácticos, las buzas, los vigilantes y los buscadores de "indios nuevos" fueron modalidades en que los españoles de Chiloé ocuparon a los chonos, su conocimiento geográfico y su dominio sobre el medio. Estas acciones, generadas para el beneficio de la corona española, produjeron profundas modificaciones al interior de grupos al alterar radicalmente el orden original del sistema económico-social, por valorar a determinados individuos que podían presentar utilidad, y ponerlos por sobre los demás. Ellos, a su vez, recibían compensaciones materiales en forma de camisas, ponchos, chaquiras, sombreros y bastones de mando, que -podemos sospechar- habrán descompensado un modo de organización que ponía especial relevancia a la minimización de las diferencias internas, y que utilizaba objetos materiales diferentes a los españoles. Se alteró también a canoeros aun no contactados, que antes de relacionarse con Chiloé lo hicieron con otros canoeros que ya portaban elementos culturales de la sociedad española o hispano-veliche, como por ejemplo el caso que describe García.

\section{Los Canoeros como Extractores y Productores de Recursos en los Archipiélagos Australes para el Comercio en Chiloé}

El gobernador de Chiloé escribió en 1773 que los indios guaiguenes y chonos

tramitan continuamente este archipiélago [de los Chonos] como ambulantes y dispersos a la pesca de lobos y mariscos. Mueven sus chozas y se alimentan de pesquería. Su genio voltario les induce continuamente a la vida andante y solo vienen a esta isla grande el tiempo de la fiesta de Santiago, donde cambian su marisco por géneros que necesitan precisamente para cubrirse, y se aprovechan de algunas papas y cebadas. No dejan de tener en aquellas islas algunos carneros y cabras. Son incapaces de vivir en sociedad e irreductibles a pueblo porque su ociosidad busca solo la libertad sin sujeción, pues Su Majestad les concedió islas inmediatas, que son las de Cailin y Chaulinec para reunirlos, y en misión para instruirlos en nuestra santa religión, pero no se ha logrado el fin por su inconstancia que aparentan mucha exterioridad de conversión y sumisión, y tal cual queda en la reducción (Beranger 1773).

Lejos de ser ociosos, para la segunda mitad del siglo XVIII podemos ver a los canoeros como activos explotadores de recursos económicos de los archipiélagos de Chonos y Guayaneco. Ya no utilizaban su medio de la misma manera que antes. Esto se debe a una progresiva adaptación a la nueva realidad impuesta, lo que comentaremos en las Conclusiones, pero quizá también a que las fuentes para ese período son más y más expresivas que las del siglo anterior. Los jesuitas les iniciaron en agricultura en Cailin y Chaulinec, agregando esta herramienta a las antiguas en un proceso que podría llamarse de hibridación (Osorio 2018).

Las actividades "europeas" que se detectan en la documentación son varias, y una de ellas es la explotación 
de naufragios. Los españoles consignaron en distintas ocasiones que los canoeros tenían o conservaban objetos de metal obtenidos de barcos europeos, por ejemplo, la "clavazón vizcaína entre los de la provincia de Allana" vista en 1640 (Rosales 1877, I:105), o clavos utilizados como herramientas para desbastar las tablas al hacer las dalcas, empleados por grupos que no habían tenido contacto con los españoles (García 1767:556).

Con ocasión del naufragio de la Wager apreciaron los objetos de metal que vieron en el campamento inglés. El gobernador de Chiloé dispuso la recuperación oficial de cañones y anclas, y por su parte los jesuitas pidieron a los recientemente trasladados a Chaulinec que fueran al naufragio a traerles metal (Urbina 2017), habilitándolos, como lo hicieron también

casi todos los vecinos de esta Provincia, pues raro será el que no haya solicitado, animado, rogado y aviado a dichos indios a fin de que les vayan a traer fierro pagándoselo muchos adelantado, ya con ciento ya con 200 y más pesos. Y no han faltado algunos que con la misma sinceridad que yo les hayan prestado piraguas. Muchos han logrado su intento pero los más han quedado burlados por la falta de fidelidad y de verdad nativa en dichos chonos (Expediente 1744:19).

Esos pesos no eran en moneda, sino en especies. Los 15 guaiguenes y sus mujeres, a quienes se les dio para tal fin una piragua de un vecino de Castro, que fue acompañada de piraguillas, recibieron de los jesuitas de Castro dos vacas, una fanega de harina de trigo, otra de cebada y 30 mazos de tabaco, y de la misión de Chequian, 30 cargas de papas. Eran especies totalmente nuevas para quienes habían llegado a Chaulinec hacía menos de un año.

También vendieron trozos de metal en la feria de Chacao, que obtuvieron directamente del naufragio, no sabemos a cambio de qué. Dice el gobernador de Chiloé en 1743: "Y porque tengo noticia han entrado estos días en la ciudad de Castro, número de piraguas de indios caucagues y otras naciones vecinas de dicho naufragio, e interesado con fierro" (Expediente 1744:5v). Los "nuevos" trasladados fueron por su cuenta al naufragio a sacar objetos de metal para venderlos, quizá porque los chonos antiguos (como Olleta), y el jesuita Flores les habían mostrado cómo el metal era valorado en Chiloé Recién llegados ya habían aprendido una nueva manera de sacar provecho del territorio del que provenían.

Así, a los recién asentados en Chiloé se les acepta su movilidad. Un año después de ser localizados en Chaulinec se dice que "han estado yendo y viniendo toda la vida y todo este año yendo y viniendo, y proseguirán yendo y viniendo" (Expediente 1744:18).
Los reportes de expediciones españolas sucesivas hacia el sur de Chiloé muestran que el sitio del naufragio se convirtió en un hito también para los canoeros, que volvían a él a sacar elementos (García encontró una bomba de la Wager en un campamento distante del naufragio) o a encontrarse entre grupos. Toda búsqueda de personas para trasladar a Chiloé va al naufragio, porque se entiende que allí es factible hallar gente. Por ejemplo, Nicolás Lobato, en su expedición de 1792, dice que en el archipiélago de los Chonos no hay habitantes, salvo los que van ocasionalmente, "pues solo donde se encuentran pueblos de indios que vagan por las playas es en el Guayaneco" (Clemente y Miró 1792:30). Hay que considerar, también, que el área del golfo de Penas era, desde antes, lugar de confluencia de grupos distintos.

Más adelante, Moraleda dejó constancia de la explotación de otro naufragio por parte de chonos. En junio de 1781 el paquebot Santo Domingo encalló en el canal Refugio, costa continental $\left(44^{\circ}\right)$. Desde Chiloé se enviaron piraguas para recoger a la tripulación y llevarse las vergas, jarcias, masteleros, etc. Se descargaron también las 18 mil tablas de alerce, que se dejaron apiladas en la orilla. Después, dice Moraleda

fueron los indios payos y guihuenes o chonos habitantes de Cailin y Chaulinec en solicitud de las tablas, que el dueño dejó al arbitrio de quien quisiere ir a tomarlas. Las han llevado a Chiloé empleándolas en la fábrica de la iglesia de Queilen y otras capillas. El año pasado se llevaron los de Cailin las últimas servibles, que tienen acopiadas para hacer la capilla de su isla (Moraleda 1796:110-111v).

Los naufragios de embarcaciones europeas fueron eventos ocasionales que podrían haber marcado verdaderos hitos geográficos e históricos en las sociedades canoeras. Son fuente de elementos materiales exógenos, materias primas que podrían incorporarse al interior de su sistema tradicional de subsistencia. Este es el caso del metal utilizado para el desbaste. Pero también, se incorporaron los naufragios en un nivel y lógica distintos, al explotarlos para extraer materiales exóticos de alto valor para el comercio. En esa práctica se evidencia el cambio de estrategia económica, con fines adaptativos, al sistema de acumulación e intercambio con el mundo español o hispano-veliche.

Los naufragios son hitos que permanecen en el tiempo, lugares a los que se vuelve, y donde se interactúa. También lo es la varazón de una ballena. Un caucahué contó a García que cuando niño fue con los suyos a comer, en el lugar donde estaba en ese momento, de una ballena que había varado, "y al mismo fin concurrió una indiada de gentiles calenches. Un mes estuvieron logrando del banquete las dos naciones. En este intermedio salieron 
once personas de los caucahues a lobear una jornada distante, siguieron los algunos calenes, y por disgustos antiguos mataron estos a todas las once personas en la misma lobería" (García 1767:562).

Una actividad productiva es la de secar pescado y marisco. Refiriéndose a los guaiguenes trasladados a Chiloé en 1743, se dice que "todo este año han estado como siempre en su antigua libertad que ha sido, el vagar por todas esas islas cogiendo lobos para comer y hacer sus lazos... y coger mariscos y pescados para secar y traer a vender entre los españoles, lo que hemos estado comprando de ellos todo este año, como los años pasados sin recelo alguno" (Expediente 1744:20v). La primera actividad extractiva, entonces, fue la de acumular pescados y mariscos y secarlos, producción de bienes destinados al intercambio, que se mantuvo en el tiempo. Moraleda apunta que los guaiguenes de Cailin y Chaulinec visitan la bahía TicToc casi anualmente para la pesca, y que en ella y en el estero de Palena había corrales de pesca (Moraleda 1796:138v y 148v).

Los canoeros en la segunda mitad del siglo XVIII tuvieron ganado en el archipiélago de los Chonos. En 1750 el ya citado guaiguen Domingo Huenupal, de quien se dice es de Puquitin, tenía 30 ovejas en la isla de Inche, cercana al sitio donde recaló el Anna, ganado que "se mantenía con la ramazón del monte y la lamilla que en él se cría" (Diario y derrotero 1750:5v). La familia Huenupal lo mantuvo en esa isla, porque Moraleda informó que sus hijos Luis y Antonio, y también Pedro Yaña, tenían ganado lanar y cabrío "en algunas [islas] vecinas a Inchemo", que nombra: Iquiloao, Quinachec, Ayaupa, Tenquehuen, Manchar y Meñauque o Inchemo (Moraleda 1792:40 y 43v). También supo Moraleda que Yaña había tenido ganado en la isla Setucapel, en la boca del estero Aysén, pero trece años atrás (en 1780), cuando abandonaron la isla Lemuy los que habían sido llevados allí en 1779, "de paso a su tierra se llevaron el ganado", que era 50 cabezas de carneros y ovejas (Moraleda 1796:46).

Otra mención a cabras en la boca del estero de Aysén la da el padre García para 1767. En una isla inmediata, llamada Calserau, un caucahue (Yaña) tenía cabras (García 1767: 522). Para aproximadamente el mismo sector (45⒊'S) del ganado de los Huenupal, la expedición de Lobato y Cuenca halló dos hombres y tres niños en una dalca, que dijeron ser de la isla de Chaulinec, quienes "estaban en esta haciendo cecina por tener en ella y en sus circunferencias ganado lanar" (Clemente y Miró 1792 :15). La evidencia arqueológica obtenida en la isla Traiguén, al sur del estero Aysén, describe antiguos corrales de pesca y cambios dietarios profundos, donde la dieta eminentemente marina es reemplazada por una mixta con incorporación de recursos terrestres luego del contacto europeo (Belmar et al 2018; Reyes et al. 2011; 2019).
Las ovejas y cabras eran para hacer de ellas charqui o tasajo, como también lo hacían de lobo marino "cuyo charque o tasajo aprecian más que el de vaca estas míseras gentes" (Moraleda 1796:78).

La extracción de grasa de lobo para venderla en Chiloé es una actividad relevante. La tenencia de ovejas y cabras en las islas dichas del archipiélago de los Chonos se complementaba con la obtención de grasa de lobo. Los chonos de Chaulinec y Cailin van cada año, o cada dos, a esas islas para hacer charque, tasajo o cecina "e igualmente se empleaban en matar lobos y sacar la grasa para venderla en San Carlos". Dice Lobato y Cuenca que hacen este viaje "por el corto lucro de 60 o 70 pesos" (Clemente y Miró 1792:15). Agrega que los indios guaiguenes "están todo el verano metidos en los canales buscando grasa de lobo donde los conduce el viento y la marea. Lo poco que se precaucionan y la barbarie con que navegan es causa de que los más de los años algunos de ellos perezcan en los peligros al cual por un lucro tan tenue se entregan, y que casualmente otras muchas veces han evadido". Concluye que son ellos los únicos que navegan el archipiélago de los Chonos, en algunos de sus canales, por el corto interés de la grasa de lobo que en ellas cogen, y el sebo y charque que hacen del ganado lanar y cabrero que han puesto en las aptas para sustentarlo (Clemente y Miró 1792:30v).

Los cuadernos del fondo Cajas Reales de Chiloé, en el Archivo General de la Nación, Lima, confirman lo apreciado por los pilotos citados. En marzo de 1787 se avisa que ha arribado a San Carlos "una piragua de indios chonos de los que anualmente ocurren a vender porción de aceite de lobos". La unidad de medida es la vejiga o panza, que se paga a 7 reales. Las 40 panzas que se compraron a los indios guaiguenes en febrero de 1790 se estima suficiente para las luces del fuerte de Chacao por un año (Cajas Reales 1787 y 1790).

Las fuentes muestran, asimismo, siembras y frutales. De las primeras hay dos referencias: cebada en una isla situada entre Guaitecas y bahía Ana Pink (Brizuela 1750:2v), y que en la isla Setucapel (boca del Aysén), Moraleda dice que el padre de Yaña, además de ganado, "tenía también algunas siembras cortas y pasaba aquí lo más del verano" (Moraleda 1796:66v). Además, en la isla de Tanhao, archipiélago de los Chonos, Moraleda vio "22 manzanos unidos que parecen de dos años de edad, con escaso fruto", plantados en orden. Atribuyó su existencia a alguno de los guaiguenes de Chaulinec y Cailin (Moraleda 1796:40).

Todas estas actividades son complementarias entre sí, y practicadas por familias, no por hombres solamente, o cuadrillas. Quienes apuntan los datos aquí consignados los ven en el archipiélago de los Chonos durante el verano. Dado que se atribuye su adscripción a Chaulinec y Cailin, el movimiento al sur es temporal: en las costas se ven rastros humanos, armazones de chozas, dalcas abandonadas, lo que da cuenta del movimiento. 
Por ejemplo, entre su paso de ida y vuelta por Puquitin, Moraleda no duda que fueron indios de Cailin quienes se llevaron unos guiones para remos dejados por él (Moraleda 1796:81v); y en la expedición de 17681769 de Sotomayor y Machado, un poco al sur de las Guaitecas hallaron un grupo de cuatro adultos y tres niños, provenientes de Cailin, quienes intentaban hacer una canoa con corteza luego que una piragua los había dejado allí aislados (Machado 1769: 4). Habían intentado huir al verlos, como lo hicieron en un canal llamado Melimeyec "unos indios de Cailin con sus mujeres e hijos, que es la costumbre que andan estos, y son los que llaman guaihuenes o chonos", dos dalcas con quienes se topó la expedición de José Rius, de 1770. Más al sur la misma expedición se encontró con otras "tres piraguas a la vela", que eran guaiguenes de Cailin, y cerca de la isla Tenquehuen, con una piragua de "guaiguenes que venían en busca de su sargentillo" (Rius 1770).

Las expediciones al área de la bahía Ana Pink, desde 1750, informan de las actividades múltiples descritas; las ejecutadas al golfo de Penas muestran la recurrente explotación del naufragio; y las que van más al sur, área de los canales Fallos, Mesier y otros, que informan de las naciones taijataf y calen (García y las tres expediciones de franciscanos siguientes), no dan cuenta de actividades de raigambre hispana o hispano-veliches en aquel sector. Pero esto no quiere decir que no se hayan practicado ni en ese momento ni después.

El archipiélago de los Chonos era un espacio que los canoeros dominaban. Era exclusivo de ellos, porque ni los españoles ni veliches practicaron actividades económicas en él (aunque si después: explotación del ciprés, caza de lobos y ballenas, etc.). La movilidad de los canoeros sustentada en su destreza tecnológica -las dalcas- y en un patrón de subsistencia borde costero y marino, fue un recurso utilizado por éstos para participar de los beneficios económicos que desde Chiloé se les hicieron atractivos.

\section{Conclusiones}

De acuerdo a lo descrito, aparte de los elementos propios del mestizaje y la asimilación cultural en contextos de contacto interétnico, nos parece destacable que los canoeros desarrollaron estrategias adaptativas de subsistencia a partir de elementos presentes en su cultura. Esto permitió a algunos grupos adecuarse a nuevas condiciones, posibilitando su presencia en medio de un contacto interétnico que finalmente los asimiló completamente. Una de estas estrategias fue la explotación de restos de naufragios, los que proveían de materiales de origen cultural exógenos, como los metales, utilizados como recursos de intercambio por ser altamente valorados en Chiloé. Otra, fue la diversificación de su economía de subsistencia hacia modalidades complementarias, como la explotación de recursos ya no solo para su consumo directo, por ejemplo, la carne del lobo marino, sino también para el comercio con españoles de Chiloé, como era la grasa de lobo para iluminación. Asimismo, la práctica de la ganadería caprina y lanar, y la agricultura de cebada y plantación de manzanos en el archipiélago de los Chonos, fue un conocimiento adquirido en Chiloé e implementado en "sus" islas orientado a la obtención de recursos para el comercio. Muy probablemente fue en las misiones donde aprendieron ambas actividades, pero habría que ponderar, también, el papel de la población veliche en ello, que desde antes de la llegada de los españoles mantenían cultivos y ganado (las "ovejas de la tierra").

Estas actividades de ganadería, cultivos y explotación de naufragios implicó la utilización de nuevos nichos ecológicos, distintos de los propiamente litorales o a las islas habituales que ofrecían en sus costas los recursos de pescados, mariscos, lobos y pájaros. Por ejemplo, otras islas, las que ofrecían pastos, ahora fueron valoradas para la crianza libre de ganado europeo, así como espacios aptos para agricultura incipiente. Implicó, asimismo, la adecuación al uso de técnicas y tecnologías de preparación y conservación de alimentos no solo para el consumo directo, como por ejemplo el ahumado y el salado (tasajo/tocino/charqui).

El traslado a los pueblos o lugares de misión en Chiloé significó un cambio en su forma de asentamiento. Pero éste, sin ser definitivamente sedentario, tuvo rangos temporales más amplios de permanencia y concentración de la población. Al mismo tiempo hubo transformaciones en las estrategias de movilidad: de una residencial alta, a una estacional de carácter logístico en el archipiélago de los Chonos, con nuevas estrategias de explotación del espacio por desplazamientos de medio y largo alcance más que desplazamientos de corto alcance. En ello jugó un papel importante la habilitación, como sistema de trato entre partes. Fue incorporada por los chonos como motivación y manera de sus navegaciones. Es probable, por lo tanto, que las dalcas de los chonos se volviesen funcionales a la variedad de actividades extractivas, como la obtención de sebo, la confección de tasajo, etc., y a la movilidad estacional, incorporando, por ejemplo, la vela española.

Por último, la valoración por parte de los foráneos del saber hacer de los canoeros sobre aquella geografía, como factor operativo y logístico de acceso y circulación por el espacio, con conocimiento de puntos específicos de obtención de recursos (lugares de naufragio o de concentración de nuevos grupos, etc.), de las rutas de navegación, de los recursos alimenticios indispensables para ello, y, en general, del laberíntico y hostil -desde el punto de vista español- espacio archipielágico, transformó ese conocimiento canoero en un producto intercambiable. Lo era porque se les gratificaba con 
bienes europeos, con el acceso a una parte de los recursos explotados, con contrapartidas de servicios personales, y con reconocimiento (categoría de cacique, nominación de "Don"). Esto, por supuesto, alteró la organización social dentro de los grupos.

Todo lo anterior permite reconocer a los grupos canoeros de los archipiélagos de Chonos y Guayaneco como un importante factor de cambio que incidió profundamente en la conformación cultural, económica e histórica no solo de los archipiélagos bordemarinos australes, sino también de Chiloé. Otros más australes, los kaweskar y yaganes, relacionándose también con poblaciones foráneas (balleneros, colonos, misioneros anglicanos, etc.) más tardíamente (siglo XIX y primera mitad del XX) no tuvieron el rol relevante y activo de los chonos. El lugar que se les otorgó fue mucho más distante y la relación más subalterna, quizá en parte por no haber mediado una población entre ambos grupos, como fue la veliche en el caso de Chiloé.

Agradecimientos: Al proyecto Fondecyt Regular $\mathrm{N}^{\circ}$ 1170726, a Miguel Chapanoff por sus valiosísimas sugerencias al texto, y a los evaluadores, por sus comentarios enriquecedores.

\section{Referencias Citadas}

Álvarez, R. 2002. Reflexiones en torno a las identidades de las poblaciones canoeras situadas entre los $44^{\circ}$ y $48^{\circ}$ de latitud Sur, denominadas 'Chonos'. Anales del Instituto de la Patagonia, Serie Ciencias Humanas 30:79-86.

Barros, A. 1975. Aborígenes australes de América. cap. 8:5759. Editorial Lord Cochrane, Santiago.

Belmar, C., O. Reyes, X. Albornoz, F. Morello y M. San Román 2018. Diet among marine hunter-gatherer-fishers of the Northern Patagonian Channels: assessing plant use and consumption through tooth calculus studies. Libro Resúmenes del 83 The Annual Meeting of the Society for American Archaeology, Washington D.C.

Byron, J. 1768. The Narrative of the Honourable John Byron: Containing an Account of the Great Distresses Suffered by himself and his Companions on the Coast of Patagonia. Impreso para S. Baker, G. Leich y T. Davies, Londres.

Casanueva, F. 1982. La evangelización periférica en el Reino de Chile. Nueva Historia 5:5-30.

Cooper, J. 1946. The Chono. En Handbook of South Amerian Indians, Vol. I, editado por J.H. Steward. The Marginal Tribes, Bureau of American Ethnology Bulletin 143: 47-54. Smithsonian Institution, Washington DC.

Moreno, R. 2008. Misiones en Chile Austral. Los Jesuitas en Chiloé, 1608-1768. Consejo Superior de Investigaciones Científicas y Universidad de Sevilla, Sevilla.

Núñez, A., R. Molina, E. Aliste y A. Bello 2016. Silencios geográficos en Patagonia-Aysén: territorio, nomadismo y perspectivas para re-pensar los márgenes de la nación en el siglo XIX. Magallania 44 (2):107-130

Osorio, M. 2018. La Economía Híbrida de los Canoeros Patagónicos: Radicación Forzada y Respuesta Indígena (1741-1800). Tesis de Licenciatura en Historia, Departamento de Ciencias Históricas, Universidad de Chile, Santiago.

Quiroz, D. y J. Olivares 1988. Nómades canoeros de la Patagonia septentrional insular: el mundo de don Pedro del Agua. En Encuentro de Etnohistoriadores, editado por O. Silva, E. Medina, E. Téllez, pp. 10-33. Universidad de Chile, Santiago.

Reyes, O. 2017. El Poblamiento del Archipielago de los Chonos $\left(43^{\circ}-47^{\circ} \mathrm{S}\right)$. Patagonia Occidental. Chile. Tesis Doctoral, Facultad de Filosofía y Letras, Universidad de Buenos Aires, Buenos Aires.

Reyes, O., M. Moraga, C. Méndez y A. Cherkinsky 2015. Maritime hunter-gatherers in the Chonos Archipelago (4350'- $46^{\circ} 50^{\prime}$ S), Western Patagonian channels. Journal of Island and Coastal Archaeology 10 (2):207-231

Reyes, O., M. San Román y M. Moraga 2011. Archipiélago de los Chonos: nuevos registros arqueológicos y bioantropológicos en los Canales Septentrionales. Isla Traiguén, XI Región de Aisén. Magallania 39 (2):295-303.

Reyes, O., M. San Román y F. Morello 2016. Search for Maritime Hunter-Gatherer Archaeological Record in the Shifting Shorelines of the South Pacific Coast (Chonos and Guaitecas Archipelago, Chile). En Marine Ventures: Archaeological Perspectives on Human-Sea Relations, editado por H. Bjerck, H. Breivik, S. Fretheim, E. Piana, B. Skar, A. Tivoli F. Zangrando, pp. 141-155. Equinox Publishing, Sheffield.

Reyes, O., A. Tessone, M. San Román y C. Méndez 2019. Dieta e isótopos estables de cazadores recolectores marinos en los canales occidentales de Patagonia, Chile. Latin American Antiquity 30 (3): 550-568.

Rosales, D. 1877 [1674]. Historia General del Reino de Chile. Flandes Indiano, Imprenta del Mercurio, Valparaíso.

Urbina, R. 1983. La Periferia Meridional Indiana. Chiloé en el Siglo XVIII. Ediciones Universitarias de Valparaíso, Valparaíso.

Urbina, R. 2007. El pueblo chono: de vagabundo y pagano alzado a cristiano y sedentario amestizado. En Orbis Incongnitus. Avisos y Legajos en el Nuevo Mundo. Homenaje al Profesor Luis Navarro García, editado por F. Navarro, I:325-346. Universidad de Huelva, Huelva.

Urbina, X. 2013. Expediciones a las costas de la Patagonia Occidental en el período colonial. Magallania 41 (2):51-84.

Urbina, X. 2016. Interacciones entre españoles de Chiloé y chonos en los siglos XVII y XVIII: Pedro y Francisco Delco, Ignacio y Cristóbal Talcapillán, y Martín Olleta. Chungara Revista de Antropología Chilena 48 (1):103-114.

Urbina, X. 2017. Traslados de indígenas de los archipiélagos patagónicos occidentales a Chiloé en los siglos XVI, XVII y XVIII. En América en Diásporas. Esclavitudes y Migraciones Forzadas en Chile y Otras Regiones Americanas (Siglos XVI-XIX), editado por J. Valenzuela, pp. 381-411. RiL editores- Instituto de Historia, Pontificia Universidad Católica de Chile, Santiago.

\section{Fuentes}

Amat y Junient 1754. Instrucción y noticia del estado en que al presente se halla el reino de Chile, que de orden del rey dio el conde de poblaciones a Don Manuel de Amat [...]. British Library (Londres), Ms. Add. 17.593, fjs. 155v-156. 
Amat y Junient c. 1760. Historia geographica e hidrographica con derrotero general correlativo al plan del reino de Chile... Real Biblioteca, Palacio Real, Madrid, MF/446.

Beranger 1771. Información de Carlos de Beranger, gobernador de Chiloé, al virrey del Perú. San Carlos de Chiloé, 4 de enero de 1771. Archivo General de Indias (Sevilla), Audiencia de Lima, Legajo 1035.

Beranger 1773. Relación Geográfica de la isla de Chiloé y su archipiélago, provincia del reino de Chile y la más austral de América Meridional... Firmada en el año de 1773. British Library, Add. Ms. 17.593 , fjs. $1-47 \mathrm{v}$.

Brizuela 1750. Diario y derrotero que hace el ayudante Manuel Brizuela de la isla de Tenqueguen en el archipiélago de los Chonos. Archivo General de Indias (Sevilla), Audiencia de Lima, Legajo 643.

Cajas Reales, Chiloé, Archivo General de la Nación (Lima), Legajo 408, cuaderno 124, San Carlos, 8 de marzo de 1787; Legajo 411, cuaderno 143, 20 de enero de 1789; y Legajo 412, cuaderno 157, San Carlos, 23 de febrero de 1790

Clemente y Miró 1792. Diario del alférez de navío de la Real Armada, D. Francisco de Clemente y Miró, comandante de la piragua Nuestra Señora del Carmen, y de la expedición destinada para reconocer el puerto de Inche o Inglés, en la costa de Chile. Archivo Histórico Nacional (Madrid), Estado, 4285, exp. 1

Expendiente sobre un conflicto entre el gobernador de Chiloe y los jesuitas por el hierro de la Wager, 1744. Archivo del Arzobispado de Santiago, Varios.

García 1767. Diario del viaje y navegación hecho por el padre Joseph García de la Compañía de Jesús desde su misión de Kaylín, en Chiloé, hacia el sur. Año 1766. En Von Murr, Cristoph Gottlieb, Nachrichten von verschiedenen Landern des spanischen Amerika, Verlegt bev Joh. Christian Hendel, Halle, 1811, pp. 506-598.

Garretón 1762. El gobernador de Chiloé, Juan Antonio Garretón, al presidente de Chile, Félix de Berroeta. Chacao, 25 de octubre de 1762. Archivo Nacional Histórico (Santiago), Capitanía General, Vol. 710, fjs. 126 y 126v.

Goicueta 1558. Derrotero y viaje de Juan Ladrillero. Archivo General de Indias (Sevilla), Patronato, 32, R. 5-1, fjs. 1-44v.

González de Agüeros 1788. Manifiesto sobre la situación, estado y circunstancias notables de la provincia y Archipiélago de Chiloé y de lo que en ella han trabajado los religiosos misioneros del colegio de Propaganda Fide de Ocopa [...] por Fray Pedro González Agüeros, 12 de agosto de 1788. Biblioteca Nacional, Manuscritos Medina, T. 207, Dcto. N5173.

González de Agüeros 1791. Descripción historial de la provincia y archipiélago de Chiloé en el reino de Chile, y obispado de la Concepción, Imprenta de Don Benito Cano, Madrid.

Gutiérrez de Espejo 1742. El gobernador de Chiloé Francisco Gutiérrez de Espejo al presidente de Chile, Manso de Velasco, Chacao, 25 de junio de 1742. Archivo General de Indias (Sevilla), Audiencia de Chile, 98.

López, "Vida del Padre Juan López Ruiz", en Rosales, Diego de, Seis misioneros en la frontera mapuche (Del Libro IV de la Conquista Espiritual del Reino de Chile, Volumen I, de Diego de Rosales), Introducción, Traducción y Notas de Gustavo Valdés Bunster, Centro Ecuménico Diego de Medellín, Ediciones de la Universidad de la Frontera, Temuco, 1991, pp. 223-233.

Machado 1768. Diario de navegación de Don Francisco Machado en la costa occidental de América del sur, Archivo del Museo Naval y Marítimo (Madrid), Manuscrito 165, fjs. 3-27v.

Moraleda 1796. Diario de la navegación desde el puerto del Callao de Lima al de San Carlos de Chiloé y de éste al reconocimiento del archipiélago de los Chonos y costa occidental patagónica comprendida entre los 41 y 46 grados de latitud meridional, hecho de real orden y comisión del Exmo. $\mathrm{Sr}$ Fr. Dn. Francisco Gil, virrey del Perú, por Dn. José de Moraleda y Montero alférez de fragata, primer piloto de la Real Armada en los años de 1792 a 1796. Tomo $2^{\circ}$. Archivo del Museo Naval de Madrid, Ms. 180.

Ovalle 1642. Memorial y carta en que el padre Alonso de Ovalle, procurador general de la Provincia de Chile, representa a N Muy Reverendo Padre Mucio Vitilesqui, prepósito general de la Compañía de Jesús, la necesidad que sus misiones tienen de sujetos para los gloriosos empleos de sus apostólicos misioneros, Sevilla, 12 de marzo de 1642, Archivum Romanum Societatis Iesu, Chile, Vol. 4.

Rius 1770. Diario de la Expedición de Joseph Rius. Archivo General de Indias (Sevilla), Audiencia de Lima, Legajo 1035.

Sobrino 1631. Letras anuas de esta provincia de Chile de los años 1629 y 30, Firmada por Gaspar Sobrino, en Santiago, 2 de abril de 1631, en Letras annuas de la vice provincia de Chile a nuestro muy reverendo padre general Gostino Nikel, escritas por el padre Juan de Albiz, vice provincial de la vice provincia de Chile desde el año de 1657 hasta el de 1659. Archivum Romanum Societatis Iesu, Chile, Vol. 6

Testimonio de los autos sobre el reconocimiento de la isla Madre de Dios y expedición que salió a este fin de la provincia de Chiloé.... Archivo General de Indias (Sevilla), Indiferente General, 412, fjs. $14 \mathrm{v}-32$.

Vea 1675. Relación diaria del viaje que se ha hecho a las costas del estrecho de Magallanes, en el recelo de enemigos de Europa, por Don Antonio de Vea, Año de 1675. Archivo del Museo Naval de Madrid, Ms. 199, fjs. 576-619. 